Copyright (C) 2018 by the Kalmyk Scientific Center of the Russian Academy of Sciences

Published in the Russian Federation
Oriental Studies (Previous Name: Bulletin of t
Humanities of the Russian Academy of Sciences)
Has been issued as a journal since 2008
ISSN: 2619-0990; E-ISSN: 2619-1008
Vol. 38, Is. 4, pp. 122-127, 2018
DOI 10.22162/2619-0990-2018-38-4-122-127
Journal homepage: https://kigiran.elpub.ru

УДК $811.58 ’ 37$

\title{
Прототипическое значение китайского глагола направления движения 上 SHÀNG
}

Александра Альбертовна Шахаева ${ }^{1}$

${ }^{1}$ кандидат филологических наук, доцент, кафедра лексикологии английского языка, факультет английского языка, Московский государственный лингвистический университет (119034, Россия, г. Москва, Остоженка, 38, стр. 1). ORCID: 0000-0003-0888-0383. E-mail: shakhaevaal@, gmail.com

Аннотация. Проблемы лексической семантики привлекают внимание многих исследователей в силу своей неоспоримой актуальности. С 1980-х гг. в науке о языке одним из ведущих направлений выделилось когнитивное изучение языка, в связи с этим семантика лексических единиц уже не рассматривается как описание статических связей между значениями и фиксация общих и дифференциальных семантических компонентов, на сегодняшний день описание семантики слова неразрывно связано с когнитивными связями и процессами мышления, обусловленными способами познания человеком, анализируя которые выявляются механизмы появления новых значений лексической единицы.

Отечественными и зарубежными исследователями в китайском языке выделяется особая группа глаголов, обладающих специфичными семантическими и грамматическими особенностями - группа глаголов направления движения. Глаголы данной группы характеризуются тем, что в их семантике содержится сема «маршрут движения». В представленной статье с точки зрения когнитивного подхода рассматривается семантика китайского глагола направления движения 上 shàng, который обладает разветвленной семантической структурой. В статье на основе диахронических данных выявляются компоненты прототипической ситуации и прослеживается их взаимосвязь с графической формой знака. Для описания семантики глагола используется набор параметров, выделенных когнитологом Л. Талми. Материалом исследования послужили данные словарей и корпуса китайского языка.

Ключевые слова: когнитивная семантика, семантическая структура, прототипическое значение, многозначность, глагол направления движения, китайский язык, иероглифический знак 
Семантика китайских глаголов направления движения, в частности, глагола 上 shàng, к сожалению, не была объектом специального изучения. Ряд зарубежных исследователей в своих работах затрагивали вопросы, связанные с когнитивным аспектом семантики глаголов данной группы, но в фокусе их исследований, в большинстве своем, были базовые глаголы направления движения 来 lái и 去 qù или семантика глаголов с позиций их функционирования в качестве модификаторов направления.

В данной статье ставится цель, опираясь на диахронические данные, описать компоненты прототипической ситуации глагола 上 shàng и определить его мотивирующее значение.

Значение иероглифического знака 上 shàng связано $\mathrm{c}$ представлениями о пространстве, пространственными отношениями. Пространство и время - это основные категории в процессе познания мира, соответственно, слова с пространственным и временным значением относятся к самому раннему пласту лексики в языке.

Исходя из истории и особенностей китайской иероглифической письменности, необходимо обратиться к исходной форме и значению иероглифического знака 上 shàng, который в современном китайском языке, наряду со значениями существительногодиректива, передает значение направленного движения вверх.

Производное значение предполагает первичное в качестве своей предпосылки, в связи с этим, изучая семантику слова, на современном этапе необходимо обращаться к диахроническим данным. Китайский язык, в силу своей иероглифической природы, при рассмотрении семантики той или иной лексической единицы требует тщательного подхода и обращения к первоначальной форме и значению иероглифического знака.

На сегодняшний день отечественные исследователи в своих работах обращали внимание на этимологию и развитие графической формы иероглифического знака 上. shàng.

Ю. В. Бунаков трактует значение пиктограммы Є следующим образом: точка или короткая линия над горизонталью, то есть нечто над горизонтом. Автор также отмечает, что данный знак обладает диффузным, нерасчлененным конкретно-абстрактным понятием [цит. по: Готлиб и др. 2014: 118].
В работе отечественного исследователя В. П. Васильева «Анализ китайских иероглифов» (1866) встречается два знака с одинаковым чтением $u_{a H^{l}}$ и одинаковым значением «верхний»: 上 и 上 [цит. по: Готлиб 2014: 10, 13]. Исследователь относит знак 上 к указательной категории знаков (к данной категории знаков В. П. Васильев относит имена прилагательные, глаголы и числительные), которые выражают «не существующий предмет, а только относящееся к нему или извлекаемое из начертания понятие» В. П. Васильев также пишет о том, что глагольное значение «подниматься» у знака появилось позднее на базе первоначального значения «верх» [цит. по: Готлиб 2014: 13].

M. В. Софронов, объясняя значение знака, пишет: «Горизонтальная линия обозначала числительное „один“, но в составе сложных знаков семантика горизонтальной линии связывалась с некоторой поверхностью. Знак „верх“ представляет собой две горизонтальные линии, из которых верхняя короче нижней. Очевидно, что нижняя линия означала поверхность, а верхняя - любой предмет на ней. Вертикальная линия не выступает в качестве самостоятельного знака. В составе сложных знаков семантика вертикальной линии менее очевидна» [Coфронов 2007: 475].

Основываясь на данных словарей Шовэнь цзецзы [Шовэнь цзецзы 1985], электронной версии словаря Шовэнь цзецзы и электронной версии иероглифического словаря Ханьюй цзыдянь [Ханьюй цзыдянь], можно сделать вывод о том, что иероглифический знак, который в современном китайском языке имеет написание 上, восходит к пиктограмме с гадательных надписей на костях и панцирях черепах $=$, которая состояла из двух горизонтальных черт, расположенных одна над другой, где нижняя, горизонтальная, символизировала Землю, верхняя - Небо, таким образом, пиктограмма передавала статическое значение, связанное с направлением к Небу.

В онлайн-словаре пиктограмм Сянсин цзыдянь, составленном на основе ведущих этимологических словарей китайского языка (Ханьюй дацзыдянь 《汉语大字典》, Шуфа цзыдянь «书法字典》, Цзягувэнь цзыдянь 《甲骨文字典》и др.), дается подробное описание этимологии и изменений графической формы знака. Составители словаря

1 Чтение знака приводится в трактовке В. П. Васильева. 
пишут о том, что древний знак, состоящий из одной горизонтальной черты, передавал значение первозданного хаоса, который, по представлениям древних китайцев, являлся великим началом.

Две горизонтальных черты, расположенные одна над другой и имеющие одинаковую длину, обозначали две противоположности: небо и землю, которые возникли из хаоса, верхняя горизонтальная обозначала небо, нижняя, соответственно, землю. С древними представлениями п небе и земле тесно связана пиктограмма $=$, которая также состоит из двух горизонтальных линий, но верхняя горизонтальная линия в данном знаке короче, чем нижняя. Данная пиктограмма в гадательных надписях на костях и панцирях черепах обозначала Небо или направление к Небу.

Наряду с данным знаком в гадательных надписях существовал знак =, где, наоборот, нижняя горизонтальная линия короче верхней, он обозначал Землю или движение в направлении к Земле [(Сянсин цзыдянь) 象形字典].

По данным словаря, следующий этап изменения графической формы знака произошел в эпоху Чжоу, когда ритуальные послания переместились на бронзовые сосуды. В надписях на ритуальных бронзовых сосудах уже встречается измененная графическая форма знака; для того чтобы отличать его от цифры два (которая записывалась также двумя горизонтальными линиями - одна над другой), у знака появляется вертикальная черта, обозначающая направление [(Сянсин цзыдянь) 象形字典]. До наших дней иероглифический знак дошел именно в указанной графической форме. Следует сказать, что знак претерпел некоторые графические изменения в стилях письма: в стиле дачжуань у знака исчезает верхняя горизонтальная s- $\perp$, в стиле чжуань знак имеет написание $\mathcal{E}$.

Китайский исследователь Ли Сюйпин отмечает, что значение иероглифа в древних гадательных надписях содержало и статический, и динамический компоненты, иероглиф употреблялся и как существительное, и как прилагательное, то есть мог выражать как локативное, так и пространственное значение. Ли Сюйпин пишет и о глагольном значении данного иероглифического знака, которое, по его мнению, передавало значение «направленного движения в пространстве по направлению с нижней точки наверх или статическое значение длительности» [Li 2006:15].

Ма Юнься на основе анализа письменных памятников древнего Китая, начиная с гадательных надписей, пришел к выводу о том, что глагольное значение изначально не было характерно для рассматриваемого иероглифа - в гадательных надписях рассматриваемый иероглифический знак принадлежал к категории существительного. Исследователь отмечает, что в доциньскую эпоху глагольное употребление знака было сравнительно небольшим, в основном знак использовался как существительное или прилагательное. По наблюдениям Ма Юнься, в конфуцианском трактате «Лунь Юй» (《论语») знак上 shàng в глагольном значении встречается три раза, а как существительное и прилагательное - девятнадцать раз, в трактате «Мэнцзы» (《孟子») в именном и качественном значениях - пятьдесят два случая, а в глагольном значении иероглиф встречается только один раз [(Ма Юнься) 马云霞 2008: 70]. Изучение случаев употребления иероглифа 上 shàng в трактатах позднего периода приводит исследователя к выводу о том, что, начиная с эпохи Западная Хань (206 г. до н. э.), 上 shàng в глагольном значении стал употребляться чаще, например, в трактате «Луньхэн» (《论 衡》) рассматриваемый иероглиф в глагольном значении встречается двадцать восемь раз, в остальных - сто семнадцать.

В современном китайском языке глагол 上 shàng является многозначным глаголом. В словаре современного китайского языка Сяндай ханьюй цыдянь [(Сяндайханьюй цыдянь) 现代汉语词典 2008] у глагола上 shàng зафиксировано 14 значений. К. В. Антонян в монографии «Морфология результативных конструкций в китайском языке», основываясь на данных словаря «Dongci yongfa cidian», говорит о 12 значениях глагола, что свидетельствует о широких полисемантических связях рассматриваемого слова [Антонян 2003: 112].

По мнению А. М. Плотниковой, многозначное слово является концептуальной структурой, которая обуславливает образование новых значений в процессе определенных операций, осуществляемых говорящим на основе существования в его сознании исходного когнитивного сценария [Плотникова 2009: 10]. О том же пишет Г. И. Кустова: «Основное, базовое, исходное значение слова, связанное с про- 
тотипической ситуацией, заключает в себе определенный способ концептуализации этой ситуации и предоставляет говорящим своего рода ментальную схему (семантическую модель) для осмысления других типов ситуаций. И эта схема лежит в основе как метафорических, так и неметафорических значений» [Кустова 2004: 122].

Таким образом, концептуальная схема является тем потенциалом, который реализуется в производных значениях лексической единицы, и непосредственно связана с прототипической ситуацией, что объясняет некое семантическое единство многозначного слова.

Выяснив этимологию и развитие значений рассматриваемого иероглифа, можно пролить свет на характеристики компонентов прототипической ситуации, лежащей в основе базового значения глагола направленного движения 上 shàng.

Под прототипической ситуацией вслед за Г. И. Кустовой [Кустова 2004] нами понимается когнитивная модель ситуации, с которой связано базовое значение языковой единицы. Опираясь на такие параметры ситуации движения, как фигура, фон, маршрут, движение, выделенные Л. Талми [Talmy 1985], когнитивная модель китайского глагола 上 shàng, на наш взгляд, включает в себя информацию о том, что фигура движется по маршруту из точки А в направлении к фону — точке Б, которая находится выше точки начала движения.

Исходя из диахронного подхода к рассмотрению графической формы и значению иероглифического знака 上 shàng, который был представлен выше, можно заключить, что первоначальное базовое значение иероглифа носило сакральный смысл и было связано с идеей неба и направления к нему. В связи с этим, на наш взгляд, важной чертой семантики глагола направленного движения 上 shàng в современном китайском языке является изменение местоположения, которое и выступает целью движения, т. е. важным аспектом характеристики компонента фона, или точки Б, является его позиция относительно начальной точки маршрута, так как цель движения фигуры - занять более высокое место по сравнению с тем, которое было в начале маршрута.

Китайские иероглифические знаки, относящиеся к идеограммам, представляют собой определенную идею, представленную изображением. М. В. Софронов пишет:
«Каждая идеограмма представляла собой, как правило, остроумное описание смысла знака в целом. Оно было текстом, единицами которого выступали элементарные знаки письма. Эти элементарные знаки в целом составляли семантический код, т. е. набор пиктограмм, которые регулярно обозначали некоторый смысл во многих идеограммах. Этот комбинаторный смысл мог отличаться от того значения, который они имели при самостоятельном употреблении» [Софронов 2007: 478].

Таким образом, можно сказать, что данный тип знаков представляет собой ментальную картину, концептуализирующую понятие окружающего мира, то есть представляет собой образ-схему ситуаций, которая отражена в семантике знака. Следовательно, китайские иероглифические знаки-идеограммы, в силу своей природы, эксплицитно содержат компоненты прототипической ситуации, которая является ресурсом семантической деривации.

Исходя из вышесказанного, мы предполагаем, что все компоненты прототипической ситуации направленного перемещения, которая содержится в базовом значении глагола, описанного выше, также эксплицитно представлены в графической форме знака 上 shàng, где нижняя горизонтальная обозначает начальную точку движения, точку А; вертикальная же черта представляет собой маршрут в направлении к фону - точке Б, которая находится выше точки начала движения и в иероглифическом знаке обозначена короткой горизонтальной.

Китайские идеограммы представляют собой ментальную картину, концептуализирующую понятие окружающего мира, то есть представляют собой образ-схему ситуации, которая отражена в семантике знака. Исходя из анализа графической формы и значений пиктограммы, послужившей прообразом современной идеограммы 上 shàng, можно сделать вывод о том, что когнитивная модель ситуации, которая лежит в основе базового значения многозначного китайского глагола направленного движения 上 shàng, мотивирована значением пиктограммы из гадательных надписей -, передающей значение направления к высшей силе - небу, а компоненты прототипической ситуации, которая содержится в базовом значении глагола, так же экспли- 
цитно представлены в графической форме знака 上 shàng, где нижняя горизонтальная обозначает начальную точку движения точку А; вертикальная черта представляет собой маршрут в направлении к фону точке Б, которая находится выше точки начала движения и в иероглифическом знаке обозначена короткой горизонтальной. Этим и объясняется цель движения фигуры по заданному маршруту - занять местоположение, которое выше положения исходной точки движения.

\section{ЛИТЕРАТУРА / REFERENCES}

Антонян 2003 - Антонян К. В. Морфология результативных конструкций в китайском языке. М.: Муравей, 2003. 268 с. [Antonyan K. V. Morfologiya rezultativnykh konstruktsiy $v$ kitayskom yazyke [Morphology of Chinese resultative constructions]. Moscow: Muravey, 2003. 268 p. (In Rus.)]

Готлиб и др. 2014 - Готлиб О. М., Кремнев E. B., Шишмарева T. Е. Отечественные труды в области грамматологии китайской письменности второй половины XIX - первой половины ХХ вв.: В. П. Васильев, С. М. Георгиевский, Ю. В. Бунаков, И. М. Ошанин. Иркутск: МГЛУ ЕАЛИ, 2014. 283 с. [Gotlib O. M., Kremnev E. V., Shishmareva T. E. Otechestvennye trudy $v$ oblasti grammatologii kitayskoj pis'mennosti vtoroy poloviny XIX pervoy poloviny $X X v v .: V$. P. Vasil'ev, S. M. Georgievskiy, Ju. V. Bunakov, I. M. Oshanin [Grammatology of the Chinese writing system: domestic works of the 1850s-1950s authored by V. P. Vasilyev, S. M. Georgievsky, Yu. V. Bunakov, I. M. Oshanin]. Irkutsk: Moscow State Linguistic Univ., Eurasian Linguistic Institute, 2014. 283 p. (In Rus.)]

Кустова $2004-$ Кустова Г. И. Типы производных значений и механизмы языкового расширения. М.: Языки славянской культуры, 2004. 472 c. [Kustova, G. I. Tipy proizvodnyh znacheniy i mehanizmy yazykovogo rasshireniia [Types of derivative meanings and language expansion mechanisms]. Moscow: Yazyki Slavianskoj Kul'tury, 2004. 472 p. (In Rus.)]

Плотникова 2009 - Плотникова А. М. Когнитивное моделирование семантики глагола (на материале глаголов социальных действий и отношений): автореф. дис. ... д-ра филол. наук. Екатеринбург, 2009. 38 с. [Plotnikova A. M. Kognitivnoe modelirovanie semantiki glagola (na materiale glagolov sotsial'nyh deystviy $i$ otnosheniy): avtoref. dis. ... dokt. filol. nauk. [Cognitive modeling of verb semantics (a case study of verbs denoting social actions and relations)]. A ScD thesis abstract. Yekaterinburg, 38 p. (In Rus.)]

Софронов 2007 - Софронов М. В. Китайский язык и китайская письменность. Курс лекций. М.: АСТ, Восток-Запад, 2007. 638 с. [Sofronov M. V. Kitaiskiy yazyk $i$ kitayskaia pis'mennost'. Kurs lektsiy [The Chinease language and its writing system. A series of lectures]. Moscow: AST, Vostok-Zapad, 2007. 638 p. (In Rus.)]

Talmy 1985 - Talmy L. Lexicalization patterns: Semantic structure in lexical forms. Language typology and syntactic description, second edition. Shopen T. (ed.) Vol. III: Grammatical categories and the lexicon. New York: Cambridge Univ. Press., 1985. Pp. 57-149. (In Eng.)

Li 2006 - Li Xuping. A lexical semantic model of verb-directional construction in Chinese - A case study of V-shang. A MA thesis. Singapore: National University of Singapore, 2006. 89 p. (In Eng.)

Ма Юнься 马云霞 2008 - 马云霞. 汉语路径动 词的演变与位移事件的表达 = Эволюция китайского глагола пути и выражение события смещения. 北京: 中央民族大学出 版社 = Пекин: Центральный университет национальной прессы, 2008. 264 с. Ма, Y. Hanyulujingdongcideyanbianyuweiyishijiande biaoda. [The evolution of Chinese path verbs and the expression of displacement events. Beijing: Central University of National Press, 2008. 264 p. (In Chin.)]

Сяндайханьюй цыдянь 现代汉语词典 2008-现 代汉语词典 $\partial u 5$ бань第 5 版 $=$ Современный китайский словарь. 北京:中国社会科学院 语言研究所词典编辑室编商务印书馆= Пекин: институт языка Китайской академии общественных наук, 2008. 1870 с. [Modern Chinese Dictionary. $5^{\text {th }}$ ed. Beijing: Institute of Linguistics, Chinese Academy of Social Sciences, 2008. 1870 p. (In Chin.)]

Шовэнь Цзецзы 说文解字 1985 - Шовэнь Цзецзы 说文解字 = Разговариваем поанглийски. У цэ 五册. 北京: 中华书局出 版社 = Пекин: Китайск. кн. изд-во, 1985. 534 c. [(Chinese) Definition dictionary. Vol. 5. Beijing: Zhonghua Book Inc., 1985. 534 p. (In Chin.)]

Шовэнь Цзецзы 说文解字 - Шовэнь Цзецзы 说 文解字. [электронный ресурс] URL: http:// www.shuowen.org/view/6 (дата обращения 19.01.2018). [(Chinese) Definition dictionary. An Internet resource: see hyperlink above (accessed: 19 January 2018). (In Chin.)] 
Ханьюй цзыдянь 汉语字典—— Ханьюй изыдянь 汉语字典 = Китайский словарь [электронный pecypc] URL: http://dict. iguci.cn/dictionary/dcontent/index/word/上 (дата обращения 06.02.2018). [Dictionary of Chinese. An Internet resource: see hyperlink above (accessed: 6 February 2018). (In Chin.)]
Сянсин цзыдянь 象形字典 - Сянсин изыдянь 象 形字典 = Словарь иероглифов [электронный pecypc] URL: http://vividict.com/WordInfo. aspx?id=2040 (дата обращения 30.01.2018). [Pictographic dictionary. An Internet resource: see hyperlink above (accessed: 30 January 2018). (In Chin.)]

UDC $811.58 ’ 37$

\title{
The Prototypical Meaning of the Chinese Directional Verb 上Shàng
}

\author{
Aleksandra A. Shakhaeva ${ }^{1}$
}

Ph.D. in Philology (Cand. of Philological Sc.), Associate Professor, Department of English Lexicology, Faculty of English Language, Moscow State Linguistic University (38/1, Ostozenka St., Moscow, 119034, Russian Federation). ORCID: 0000-0003-0888-0383. E-mail: shakhaevaal@gmail.com

\begin{abstract}
Chinese characters - ideograms - represent a mental picture conceptualizing the notion of the surrounding world, that is, they represent an image-schema of the situation which is reflected in the semantics of the sign. The article describes components of the prototypical situation of the Chinese verb and determines its motivating significance with evidence from analysis of diachronic data. The paper reveals that the prototypical situation of the verb 上 shàng is motivated by the meaning of the pictogram from divinatory inscriptions containing the meaning of direction towards the higher power - the sky (Heaven). A hypothesis set forth that components of the prototypical situation contained in the basic meaning of the verb are also explicitly represented in the graphic form of the 上 shàng sign, and the components of the prototypical situation contained in the basic meaning of the verb are also explicitly represented in the graphical form of the sign where the lower horizontal sign indicates the starting point of the movement - point $A$; the vertical line is the route towards the background - point $\mathrm{B}$, which is above the starting point of the movement and is indicated by a short horizontal line in the hieroglyphic sign. This explains the purpose of moving the figure along the given route - to take a position higher than the position of the starting point of the movement.
\end{abstract}

Keywords: cognitive semantics, prototypical situation, basic meaning of a verb, image-schema, Chinese directional verb, Chinese characters 